\title{
Hospital-acquired pressure ulcers in spinal cord injured patients: time to occur, time until closure and risk factors
}

\author{
H van der Wielen ${ }^{1,2}$, MWM Post ${ }^{3,4,5}$, V Lay $^{3}, K_{\text {Gläsche }}^{1}$ and A Scheel-Sailer ${ }^{1,6}$
}

\begin{abstract}
Study design: Prospective observational cohort study.
Objectives: To describe time to occur and time until closure of hospital-acquired pressure ulcers (HAPUs) in patients with spinal cord injury $(\mathrm{SCl})$.

Setting: Specialised SCl acute care and rehabilitation clinic in Switzerland.

Methods: Daily registration of the presence and severity of HAPUs in a consecutive sample of $\mathrm{SCl}$ patients during their entire in-patient stay.

Results: Out of 185 observed SCl patients, 55 patients (29.7\%) developed at least one HAPU. Within the first 30 days after admission, $50 \%$ of all HAPUs occurred. Less severe HAPUs occurred earlier than severe HAPUs. The occurrence of HAPUs was significantly associated with reason of admission $(P<0.01)$, and was highest in first rehabilitation $(51.4 \%)$ and orthopaedic surgery patients (41.4\%). The incidences of first HAPU in these groups were 1.04 and 2.31 per patient-year, respectively. Patients in first rehabilitation or readmitted because of pressure ulcer (PU) showed an initial lower risk for HAPUs in the Kaplan-Meier curve compared with patients readmitted for other reasons. Cox regression analysis revealed an association between longer time since $\mathrm{SCl}$ and time until occurrence $(P=0.01)$. Closure of the HAPUs during hospitalisation was observed in 37 patients $(67.3 \%)$ after 38.9 days on average. No significant associations were found between patient characteristics and time until closure.
\end{abstract}

Conclusion: The dynamics of HAPUs varied according to admission reason and time since lesion. However, ongoing awareness to prevent HAPUs is needed in all patients with SCI.

Spinal Cord (2016) 54, 726-731; doi:10.1038/sc.2015.239; published online 19 January 2016

\section{INTRODUCTION}

A frequent occurrence of pressure ulcers (PUs) during hospitalisation of patients with a spinal cord injury (SCI) has been reported in the literature, varying from 36 to $49.2 \%$ in recent publications. ${ }^{1-3}$ Although many in-patient prevention concepts have been developed, being admitted to a hospital or rehabilitation centre is still a risk factor for hospital-acquired pressure ulcers (HAPUs). ${ }^{4}$ HAPUs are associated with high hospital costs because of prolonged hospital stay ${ }^{5}$ and need for additional materials and nursing time. ${ }^{6}$ Being discharged from the rehabilitation hospital without wound closure is associated with reduced functional outcomes ${ }^{7}$ and an increased risk of complications in patients with SCI. ${ }^{8}$ Therefore, reducing the occurrence and shortening the time until closure of PUs is important to reduce patient's burden and health-care costs.

In a cohort study in eight Dutch rehabilitation centres, 36.5\% participants obtained a HAPU during the acute rehabilitation phase and $39.4 \%$ participants during functional rehabilitation. ${ }^{1,3}$ However, studies in non-SCI patients showed that HAPUs occurred relatively early after admission, varying from $6.2 \%$ within 2 days of admission ${ }^{9}$ to $12.4 \%$ within 7 days on admission to an intensive care unit. ${ }^{10}$ On average, less severe HAPUs occurred earlier than severe HAPUs on intensive care units. ${ }^{11}$ Events, such as a surgery, are known to enhance the risk of HAPUs in all and especially in SCI patients. ${ }^{12-14}$

Complete healing of a $\mathrm{PU}$ is difficult to determine because molecular and cellular processes of healing continue for months after the epithelial covering. Therefore, measuring the closure of a PU is a more pragmatic approach. Closure of a PU has been defined as complete epithelialisation, with a thin, unstable and translucent skin without a fully restored epidermal integrity and stability. ${ }^{15}$ There are only few descriptive data on time until closure of HAPUs in SCI patients. ${ }^{16}$ Information from other populations is only marginally applicable, as healing of PUs in SCI patients takes more time because of physiological changes in the wound-healing cascade. ${ }^{17}$

The aim of this study is (1) to analyse the time between admission and occurrence of HAPUs in SCI patients in a specialised acute care and rehabilitation clinic for SCI and (2) to analyse the time until closure of these HAPUs.

\section{MATERIALS AND METHODS \\ Research design \\ Information on the presence of PU was collected prospectively from daily observations, and registered information on risk factors was collected retro- spectively from medical files. Data on occurrence, localisation and risk factors}

${ }^{1}$ Swiss Paraplegic Centre, Nottwil, Switzerland; ${ }^{2}$ Merem Behandelcentra, De Trappenberg, Huizen, The Netherlands; ${ }^{3}$ Swiss Paraplegic Research, Nottwil, Switzerland; ${ }^{4}$ University of Groningen, University Medical Center Groningen, Center for Rehabilitation, Groningen, The Netherlands; ${ }^{5}$ Brain Center Rudolf Magnus and Center of Excellence in Rehabilitation Medicine, De Hoogstraat Rehabilitation and University Medical Center Utrecht, Utrecht, The Netherlands and ${ }^{6}$ Department of Health Sciences and Health Policy, University of Lucerne, Lucerne, Switzerland

Correspondence: Dr A Scheel-Sailer, Swiss Paraplegic Centre, Guido A Zäch Strasse 1, Nottwil 6207, Switzerland.

E-mail: anke.scheel@paraplegie.ch

Received 11 May 2015; revised 16 November 2015; accepted 10 December 2015; published online 19 January 2016 
of PU have been reported in a previous article in this journal using the same database. ${ }^{2}$ In addition, the current paper contributes a longitudinal perspective, analysing time until occurrence and time until closure of PU.

\section{Patients}

Data for this study were collected from a consecutive sample of patients with SCI admitted for in-patient treatment to the Swiss Paraplegic Centre, Nottwil, Switzerland, between September 2009 and February 2010. Included were all patients who were at least 18 years old and had an SCI classified as American Spinal Injury Association Impairment Scale (AIS) A-D. No exclusion criteria were applied. All HAPUs were treated conservatively in line with the house interne concept. The main principles of this concept include, firstly, pressure

Table 1 Baseline characteristics of the study population and the subgroup of patients with HAPUs

\begin{tabular}{|c|c|c|c|c|c|}
\hline \multirow[t]{2}{*}{ Characteristic } & \multicolumn{2}{|c|}{$\begin{array}{l}\text { All patients } \\
\qquad \mathrm{N}=185\end{array}$} & \multicolumn{2}{|c|}{$\begin{array}{c}\text { With HAPU } \\
\qquad N=55\end{array}$} & \multirow{2}{*}{$\begin{array}{c}\text { Test } \\
\text { P-value }\end{array}$} \\
\hline & $\mathrm{N}$ & $\%$ & $\mathrm{~N}$ & $\%$ & \\
\hline \multicolumn{6}{|l|}{ Gender } \\
\hline Female & 50 & 27.0 & 13 & 26.0 & 0.314 \\
\hline Male & 135 & 73.0 & 42 & 31.1 & \\
\hline \multicolumn{6}{|l|}{ Age at admission (years) } \\
\hline $18-35$ & 46 & 24.9 & 9 & 19.6 & 0.234 \\
\hline $36-50$ & 58 & 31.4 & 19 & 32.8 & \\
\hline $51-65$ & 60 & 32.4 & 18 & 30.0 & \\
\hline 66 or above & 21 & 11.4 & 9 & 41.9 & \\
\hline \multicolumn{6}{|l|}{ Time since lesion (years) } \\
\hline 0 & 34 & 18.4 & 16 & 47.1 & 0.002 \\
\hline $1-5$ & 38 & 20.5 & 7 & 18.4 & \\
\hline $6-25$ & 65 & 35.1 & 12 & 18.5 & \\
\hline 26 or above & 48 & 25.9 & 20 & 41.7 & \\
\hline \multicolumn{6}{|l|}{ Aetiology } \\
\hline Traumatic & 130 & 70.3 & 39 & 30.0 & 0.525 \\
\hline Nontraumatic & 55 & 29.7 & 16 & 29.1 & \\
\hline \multicolumn{6}{|l|}{ Lesion level } \\
\hline Paraplegia & 108 & 58.4 & 29 & 26.6 & 0.197 \\
\hline Tetraplegia & 77 & 41.6 & 26 & 34.2 & \\
\hline \multicolumn{6}{|l|}{ AIS injury severity } \\
\hline A & 121 & 65.4 & 41 & 33.9 & 0.069 \\
\hline$B-D$ & 64 & 34.6 & 14 & 21.9 & \\
\hline \multicolumn{6}{|l|}{ PU at admission } \\
\hline No & 126 & 69.1 & 32 & 25.4 & 0.060 \\
\hline Yes & 59 & 31.9 & 23 & 39 & \\
\hline \multicolumn{6}{|l|}{ Reason for admission } \\
\hline First rehabilitation & 35 & 18.9 & 18 & 51.4 & 0.006 \\
\hline Readmission for PU & 25 & 13.5 & 8 & 32.0 & \\
\hline Orthopaedic surgery & 29 & 15.7 & 12 & 41.4 & \\
\hline Urologic surgery & 29 & 15.7 & 2 & 6.9 & \\
\hline Re-rehabilitation & 32 & 17.3 & 8 & 25.0 & \\
\hline Other readmissions & 35 & 18.9 & 7 & 20.0 & \\
\hline
\end{tabular}

Abbreviations: AIS, American Spinal Injury Association Impairment Scale; HAPU, hospitalacquired pressure ulcer; $\mathrm{PU}$, pressure ulcer.

${ }^{a}$ Comparison of patients with and without HAPU; Fisher's exact test for $2 \times 2$ tables and $\chi^{2}$ test otherwise. relief adapted to the location of the PU and the personal situation of the patient. This may include bed rest, special pressure relief mattress and repositioning protocol. Secondly, according to the wound assessment URGE principles $(\mathrm{U}=$ Wund $u$ mgebung, $\mathrm{R}=$ Wund $r$ and, $\mathrm{G}=$ Wundgrund, $\mathrm{E}=$ Exsudat), ${ }^{18,19}$ nurses and rehab physician initiate the local wound therapy following the TIME concept $(\mathrm{T}=$ tissue removal, $\mathrm{I}=$ infection control, $\mathrm{M}=$ moisture management, $\mathrm{E}=$ edge protection). ${ }^{20}$ An individual risk assessment is made including patient's characteristics, comorbidities such as diabetes, peripheral arterial occlusive disease, infections and incontinence, local factors such as contamination and moisture, nutrition status with blood examination by a dietician and psychosocial status. In case of severe HAPU (grade 3 or more, recurrent or a nonhealing grade 2) with a potential indication of surgery, the in-house plastic surgeon was consulted.

\section{Procedure}

Patients were examined for the presence of PU every $12 \mathrm{~h}$ during their entire hospitalisation.

\section{Instruments}

Only PUs that occurred during admission were considered. The presence and severity of HAPUs were recorded using a documentation sheet and later entered into an access database. HAPUs were graded according to the EPUAP (European Pressure Ulcer Advisory Panel) classification. ${ }^{21}$ Patient characteristics such as gender, age at admission, AIS score, level of injury, time since onset of the lesion, aetiology of injury and reason for admission were retrieved from medical files.

\section{Analysis}

Time until occurrence of HAPU was defined as the number of days from admission to the first observation of the first or second HAPU. Time until closure was defined as the number of days from the first observation of the HAPU until assessment of grade 0 with complete epithelialisation was assessed for the first time. ${ }^{15}$ Locations were grouped into foot (toe, heel, forefoot, ankle), lower extremity (legs), sitting area (sacrum/coccyx, ischium, trochanter, genitals, groin) and other (back, head etcetera). Reason for admission was categorised into first rehabilitation, readmission for treatment of PU and readmission for other reasons.

Nonparametric tests were applied to test for the associations between patient characteristics and the occurrence of HAPU ( $\chi^{2}$ and Fisher's exact test $)$ and time until occurrence of HAPU (Mann-Whitney and Kruskal-Wallis test). Length of stay with and without HAPU and the occurrence of HAPU per patient-months and patient-years were described. Time until occurrence of HAPU according to reason for admission group is presented in a box plot. Time until occurrence of HAPU by admission reason and categories of time since lesion $(0-5,6-25,26$ or more years) is displayed in Kaplan-Meier plots. Cox regression analysis was performed to identify independent determinants of time until occurrence of HAPU, including all variables that are bivariate significantly associated with time until occurrence of HAPU in the analysis.

Time until closure or until discharge without closure of HAPU according to the EPUAP classification is displayed in a box plot and potential determinants for discharge without closure were tested using $\chi^{2}$ and Fisher's exact test. The significance level was set at $5 \%$. All analyses were performed with SPSS version 21 (IBM Corp., Armonk, NY, USA).

The study protocol was approved by the local ethical committee of Lucerne (registration number 11095).

\section{RESULTS}

A total of 185 patients were included in the study and observed during their entire hospitalisation. Their characteristics are displayed in Table 1. Of this group, 55 patients $(29.7 \%)$ developed one or more HAPUs. The severity of HAPU was grade 1 in 17 (30.9\%), grade 2 in $32(58.2 \%)$ and grade 3 in 6 patients $(10.9 \%)$. Out of the 55 patients who developed HAPUs, 27 patients developed second HAPU, and in 25 patients at a different location. Most secondary HAPU occurred in patients admitted for first rehabilitation (Supplementary Table 1). 
Table 2 Occurrence of a first HAPU classified by admission reason

\begin{tabular}{|c|c|c|c|c|c|}
\hline \multirow[t]{2}{*}{ Reason for admission } & \multicolumn{2}{|c|}{$\begin{array}{c}\text { All patients } \\
(\mathrm{N}=185)\end{array}$} & \multicolumn{2}{|c|}{$\begin{array}{l}\text { Patients with } \\
\text { HAPU }(\mathrm{N}=55)\end{array}$} & \multirow[t]{2}{*}{$\begin{array}{c}\text { HAPU (per patient- } \\
\text { years) }\end{array}$} \\
\hline & $\mathrm{N}$ & Mean LOS & $\mathrm{N}$ & Mean LOS & \\
\hline Readmission for PU & 25 & 91.7 & 8 & 132.8 & 1.273 \\
\hline First rehabilitation & 35 & 181.1 & 18 & 218.4 & 1.036 \\
\hline Re-rehabilitation & 32 & 50.4 & 8 & 90 & 1.811 \\
\hline Orthopaedic surgery & 29 & 65.5 & 12 & 108.2 & 2.308 \\
\hline Urologic surgery & 29 & 13.4 & 2 & 14 & 1.881 \\
\hline Other & 35 & 44.1 & 7 & 75.1 & 1.655 \\
\hline
\end{tabular}

Abbreviations: HAPU, hospital-acquired pressure ulcer; LOS, length of stay (in days);

$\mathrm{PU}$, pressure ulcer.

The occurrence of HAPU was associated with reason for admission, time since lesion (Table 1) and length of stay (all: $P<0.01$ ). HAPUs were most frequently seen in patients admitted for first rehabilitation (51.5\%), orthopaedic surgery $(41.4 \%)$ and treatment of pre-existing PU (32.0\%). Expressed in patient-years, the incidence of HAPU was highest in orthopaedic patients (2.31 HAPUs per person-years; Table 2).

As an unexpected occurrence of third-grade HAPU was found, documentation sheets were checked in detail. Furthermore, location of HAPU, diagnosis, laboratory and treatment context of these patients were retrieved from the medical files, but no pattern was found. All six patients were multimorbid with varying comorbidities and one thing common in all was that they were treated with antibiotics for $>24 \mathrm{~h}$ because of acute or chronic infection or surgery. In three patients, this was facilitated with a rise of infection parameters at the time of occurrence.

\section{Time until occurrence of HAPU}

Within 30 days after admission, 50\% of all first HAPUs occurred. The median time from admission until occurrence for grade 1, 2 and 3 HAPUs was 19, 31 and 62 days, respectively (Table 3). In comparison, patients admitted for PU or first rehabilitation showed a lower occurrence of HAPU during the first weeks of hospitalisation than patients who were readmitted for other reasons (Table 3 and Figures 1 and 2). In orthopaedic patients, HAPU occurred in 25\% within $24 \mathrm{~h}$ post surgery and in $66.7 \%$ within 5 days post surgery.

No significant association between reason for admission and time until occurrence of HAPU was found using Cox regression analysis; however, time since lesion was significantly associated with occurrence of HAPU (Table 4). Different survival curves were found for the three groups of time since lesion, showing a higher risk to suffer from a HAPU within the first days after admission and for patients having a lesion for several years since lesion for example (Figure 3 ).

The mean time between occurrence of the first and the second HAPU was 40 days (s.d. 26.6 days). Of the 27 second HAPUs, 14 occurred before closure of the first HAPU. The mean and median time from admission until occurrence of a second HAPU was 87.6 and 72 days, respectively (Supplementary Table 1).

\section{Time until closure of a HAPU}

Of all HAPUs, 37 (67.3\%) closed completely during hospital stay. The majority of the patients without closed wounds (15 patients, $83 \%$ ) were discharged to their homes. The median time until closure during hospital stay was 31 days (interquartile range 20-62 days;
Table 3 Time until occurrence of the first HAPU (days)

\begin{tabular}{lccccc}
\hline & N & Median & IQR & Min-max & P-value \\
\hline $\begin{array}{l}\text { All patients with HAPU } \\
\text { Gender }\end{array}$ & 55 & 30 & $8-74$ & $1-186$ & \\
$\quad$ Female & 13 & 32 & $11-77$ & $2-138$ & 0.736 \\
$\quad$ Male & 42 & 28 & $7-71$ & $1-186$ & \\
& & & & & \\
Age at admission (years) & & & & & \\
$\quad$ 18-35 & 9 & 67 & $12-77$ & $4-174$ & 0.135 \\
$36-50$ & 19 & 8 & $9-45$ & $1-186$ & \\
$51-65$ & 18 & 44.5 & $18-77$ & $6-149$ & \\
66 or above & 9 & 24 & $19-70$ & $3-129$ & \\
& & & & &
\end{tabular}

Time since lesion (years)
0

$1-5$

$6-25$

26 or more

Aetiology

Traumatic

Nontraumatic

Lesion level

Paraplegia

Tetraplegia

AlS injury severity

A

B-D

Reason for admission

First rehabilitation

Readmission for PU

Re-rehabilitation

Orthop./urol. surgery

Other readmissions

Localisation

Sitting area

Lower extremity

Foot

Other

$\mathrm{PU}$ at admission

No

Yes

Grade of first HAPU

$\begin{array}{lcccc}1 & 17 & 19 & 8-49 & 1-138 \\ 2 & 32 & 31 & 7-77 & 2-186 \\ 3 & 6 & 62 & 42-83 & 10-149\end{array}$

$<0.001$

$18-103$

1-58

$\begin{array}{cc}3-19 & 1-58 \\ 5.5-67.5 & 2-149\end{array}$

$1.5-74 \quad 1-186$

4.5-77 2-129

0.317

0.423

8-59 2-186

8-71 2-138

0.643

$41 \quad 27.0$

10-84 1-186

2-186

6-149

3-43

2-77

1-91
Abbreviations: AIS, American Spinal Injury Association Impairment Scale; IQR, interquartile range; HAPU, hospital-acquired pressure ulcer; Min-max, minimum-maximum; Orthop./urol., orthopaedic/urologic; PU, pressure ulcer.

aMann-Whitney and Kruskall-Wallis test.

Supplementary Table 2). The median time until closure for grade 1, 2 and 3 HAPUs was 25, 34 and 39 days, respectively. The longest time until closure was found in patients admitted for first rehabilitation (median: 64 days, interquartile range 30-72 days). 


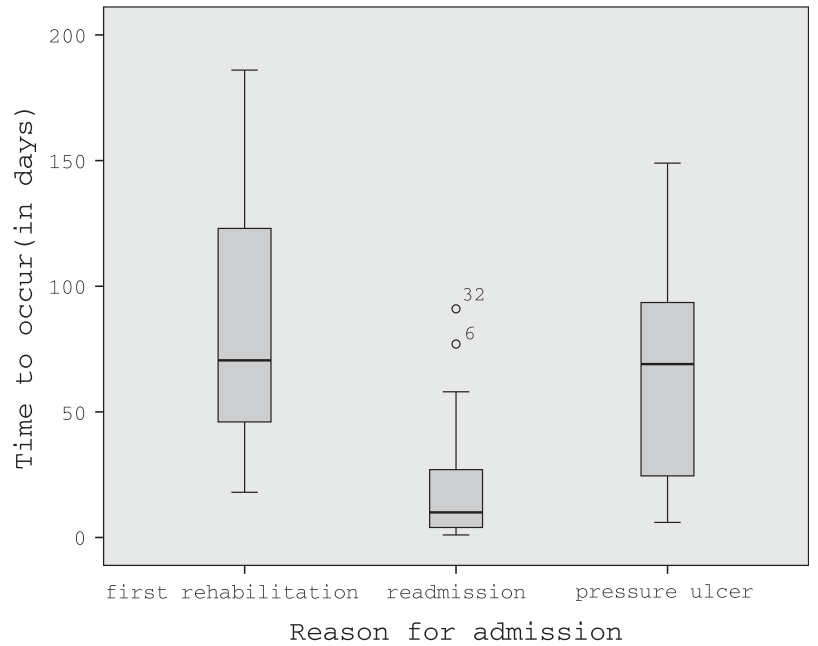

Figure 1 Time until occurrence of HAPU per admission reason. A full color version of this figure is available at the Spinal Cord journal online.

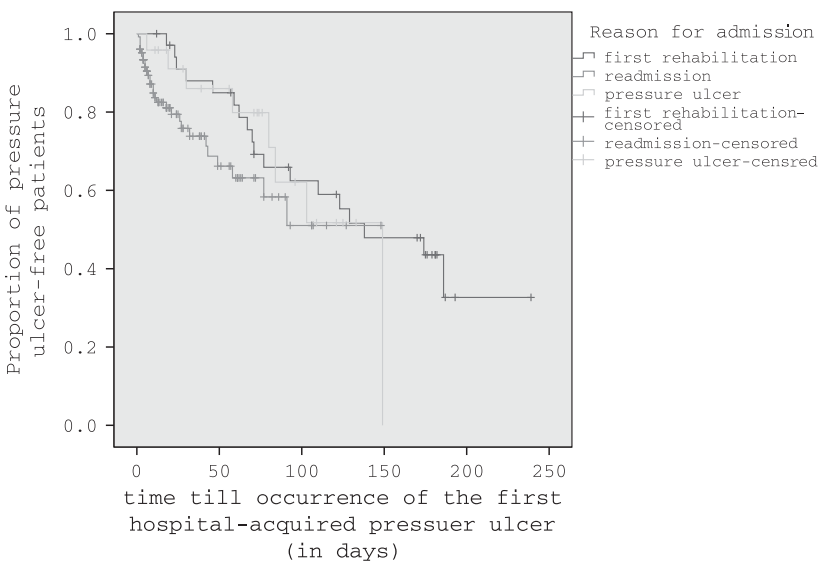

Figure 2 Survival curve for time until occurrence of HAPU by reason for admission $(N=185)$. A full color version of this figure is available at the Spinal Cord journal online.

None of the tested characteristics were associated with being discharged with or without closure of the HAPU (Table 5). Reasons for incomplete closure as retrieved from medical files varied from a slow healing progress due to co-morbidities (including diabetes, psychiatric disorders and malignant diseases with poor prognosis) or death. There was a wide range of time until discharge of patients discharged with nonclosed wounds (Figure 4).

\section{DISCUSSION}

Based on high-quality observational data, we observed that nearly $30 \%$ of all SCI patients developed a HAPU during hospitalisation, in which $50 \%$ occurred during the first 30 days of admission. There was a wide range of time until occurrence of a HAPU, with different Kaplan-Meier curves for groups of time since lesion and reason for admission.

This high occurrence rate suggest that not all PUs can be avoided, as it has been concluded by the NPUAP (National Pressure Ulcer Advisory Panel) in 2014. ${ }^{21}$ Several studies have tried to give an overview about the circumstances when HAPUs occur ${ }^{1,3}$ by doing retrospective analysis over periods of 3 months or divide occurrences in different rehabilitation phases. By knowing and confirming the
Table 4 Cox regression for time until occurrence of HAPU $(N=185$, 55 events)

\begin{tabular}{lcccc}
\hline Characteristic & Odds ratio & $95 \% \mathrm{Cl}$ & Wald & P-value \\
\hline $\begin{array}{l}\text { Time since lesion (years) } \\
\text { Reason for admission }\end{array}$ & 1.04 & $1.01-1.06$ & 8.07 & 0.005 \\
$\quad$ First rehab (reference) & - & & & \\
$\quad$ Readmission for PU & 2.03 & $0.91-4.54$ & 2.97 & 0.085 \\
$\quad$ Readmission for other reasons & 2.29 & $0.78-6.72$ & 2.27 & 0.132 \\
\hline
\end{tabular}

Abbreviations: $\mathrm{Cl}$, confidence interval; HAPU, hospital-acquired pressure ulcer; $\mathrm{PU}$, pressure ulcer; rehab, rehabilitation.

$R^{2}=0.07$, likelihood ratio test: test statistic $=13.91, P=0.03$

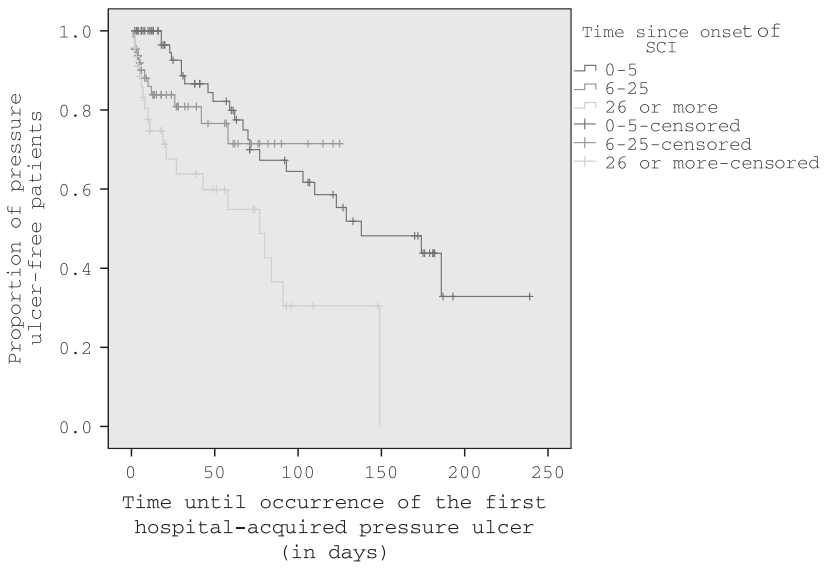

Figure 3 Survival curve for time until occurrence of HAPU by time since lesion. A full color version of this figure is available at the Spinal Cord journal online.

influence of length of stay, ${ }^{4,5}$ our daily-based observations put perspective about the influence of time on the development of HAPU.

\section{Time until occurrence}

Of all PUs, 50\% occurred during the first 30 days after admission. Early development of PU after hospitalisation is well known in nonSCI cohort studies, ${ }^{9,10}$ reporting similar or even less time until occurrence. In our SCI population, earlier PU development was mainly seen in patients readmitted for surgery, re-rehabilitation or acute care, leading to a significant association of admission reason with time until occurrence $(P<0.001$, Table 3$)$.

Surgery $(>4 \mathrm{~h})$ is a risk factor for HAPU in $\mathrm{SCI}^{12,13}$ and an indicator of the presence of secondary health conditions. ${ }^{12,22}$ Focussing on highest occurrence per patient-years, our orthopaedic SCI patients had more HAPUs in the immediate postoperative period than non-SCI patients $(25 \% \text { versus } 5 \%)^{14}$ and a similar rates after 5 days of surgery $(66.7 \%$ versus $58 \%) .{ }^{14}$ Even though surgery is of influence, not all patterns can be explained; for example, low incidences in patients admitted for deep PUs that were almost all surgically closed. Regarding our small sample size of surgical patients, further research on HAPU after surgery in SCI is recommended.

The influence of prevention and therapeutic concepts may also explain the different time dynamics found for HAPU in first rehabilitants and patients admitted for PU treatment. Immobilisation post surgery/lesion and slow mobilisation in cumulative steps afterwards, in combination with more self-responsibility before discharge and in later phases of rehabilitation, may lead to different patterns of 
Table 5 Determinants of discharge without closure of the first HAPU $(N=55)$

N Discharge without closure (\%) Test statistica P-value

\begin{tabular}{|c|c|c|c|c|}
\hline All patients with HAPU & 55 & 32.7 & & \\
\hline \multicolumn{5}{|l|}{ Gender } \\
\hline Female & 13 & 38.5 & & \multirow[t]{2}{*}{0.426} \\
\hline Male & 42 & 31.0 & & \\
\hline \multicolumn{5}{|c|}{ Age at admission (years) } \\
\hline $18-35$ & 9 & 55.6 & \multirow[t]{4}{*}{6.34} & \multirow[t]{4}{*}{0.096} \\
\hline $36-50$ & 19 & 21.0 & & \\
\hline $51-65$ & 18 & 44.4 & & \\
\hline 66 or above & 9 & 11.1 & & \\
\hline \multicolumn{5}{|c|}{ Time since injury (years) } \\
\hline 0 & 16 & 31.3 & \multirow[t]{4}{*}{0.12} & \multirow[t]{4}{*}{0.989} \\
\hline $1-5$ & 7 & 28.6 & & \\
\hline $6-25$ & 12 & 33.3 & & \\
\hline 26 or more & 20 & 35.0 & & \\
\hline \multicolumn{5}{|l|}{ Aetiology } \\
\hline Traumatic & 39 & 31.3 & & \multirow[t]{2}{*}{0.572} \\
\hline Nontraumatic & 16 & 33.3 & & \\
\hline \multicolumn{5}{|l|}{ Lesion level } \\
\hline Paraplegia & 29 & 27.6 & & \multirow[t]{2}{*}{0.284} \\
\hline Tetraplegia & 26 & 38.5 & & \\
\hline \multicolumn{5}{|l|}{ AIS injury severity } \\
\hline A & 41 & 21.4 & & \multirow[t]{2}{*}{0.241} \\
\hline$B-D$ & 14 & 36.6 & & \\
\hline \multicolumn{5}{|l|}{ Reason for admission } \\
\hline First rehabilitation & 18 & 33.3 & 3.66 & \multirow[t]{5}{*}{0.454} \\
\hline Readmission for PU & 8 & 25.0 & & \\
\hline Re-rehabilitation & 8 & 12.5 & & \\
\hline Orthop./urol. surgery & 14 & 35.7 & & \\
\hline Other readmissions & 7 & 57.1 & & \\
\hline \multicolumn{3}{|l|}{ Localisation } & 0.988 & \multirow[t]{5}{*}{0.804} \\
\hline Sitting area & 24 & 29.9 & & \\
\hline Lower extremity & 6 & 33.3 & & \\
\hline Foot & 20 & 40.0 & & \\
\hline Other & 5 & 20.0 & & \\
\hline \multicolumn{3}{|l|}{ PU at admission } & & \multirow[t]{3}{*}{0.285} \\
\hline No & 32 & 28.1 & & \\
\hline Yes & 23 & 39.1 & & \\
\hline \multicolumn{5}{|l|}{ Grade of first HAPUa } \\
\hline 1 & 17 & 29.4 & 3.52 & 0.171 \\
\hline 2 & 32 & 28.1 & & \\
\hline 3 & 6 & 66.7 & & \\
\hline
\end{tabular}

Abbreviations: AIS, American Spinal Injury Association Impairment Scale; HAPU, hospitalacquired pressure ulcer; Orthop./urol., orthopaedic/urologic; PU, pressure ulcer.

aThe $\chi^{2}$ or Fisher's exact test.

HAPU development. Detailed analyses of risk factors and treatment concepts for comparison are still missing. ${ }^{23}$

In our sample, higher proportions of HAPUs were observed within the first year after lesion and 26 years post lesion. Our survival curves also stress a higher risk during hospitalisation for patients with longer time since lesion. The significant, positive association with time

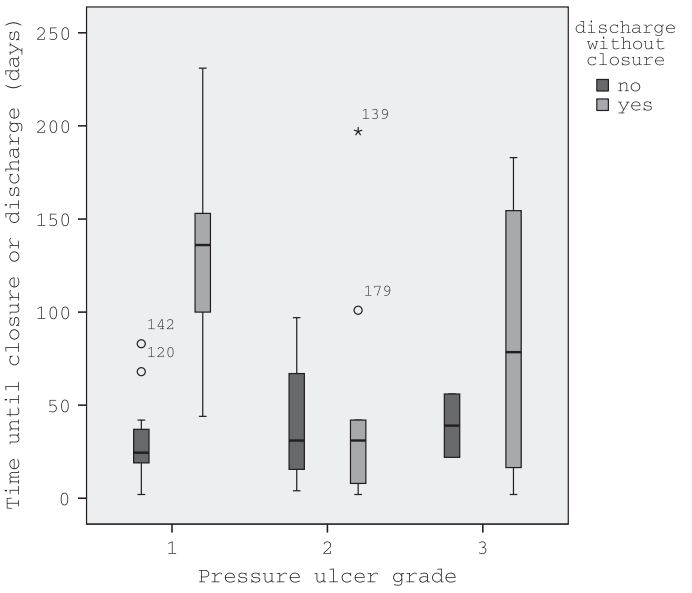

Figure 4 Time from occurrence until closure or discharge. A full color version of this figure is available at the Spinal Cord journal online.

since injury $(P=0.005)$ is corresponding with results found in literature. ${ }^{11,15,22}$

\section{Time until closure}

The therapeutic goal and principles of treatment usually lead to healing of a PU ulcer during hospitalisation. The rehabilitation team and patients decided for conservative treatment of all HAPUs, even though plastic surgery was easily accessible. Reasons to omit surgical treatment varied from a bad health condition to the patient's wish not to be operated or to go home with a nonhealed wound grade 2 or 3 . Comparing time until closure in our study with the literature, ${ }^{16,23,24}$ our median time was lower $\left(69^{24}\right.$ and $\left.49^{23}\right)$ in comparison with 31 days in our study). However, these comparisons are hampered by several reasons such as different patient characteristics, physiological changes in SCI patient, ${ }^{17}$ changes in treatment protocols over time and pre-existing wounds. The closure time was 2-97 days, underlining the difficulties to predict it based on severity grade. Using size measurement, ${ }^{16}$ wound closure can be analysed more carefully.

Discussing our results, we have to consider that $32.7 \%$ of our patients were discharged without complete closure of their HAPU. Some patients can be discharged when the original rehabilitation goals like a planned surgery or treatment of an infection or pain are accomplished and closure before discharge is not always needed. Because of economic pressure, the problem of unclosed pressure ulcers at discharge is increasingly reported. ${ }^{8,25}$ In our population as an example of the Swiss health-care system, the proportion of patients with open HAPU $(32.7 \%)$ was lower at the time of discharge than in other populations $(50 \%, 54.1 \%) .8,25$ Economic and politic factors, ethical considerations, vision of the institution and caregivers in the Swiss health-care system influence this rate, allowing patients an ongoing in-house treatment until closure. ${ }^{7,22}$ Although occurrence of $\mathrm{PU}$ is often discussed as an indicator of worse outcome and discharge destination, ${ }^{4,7}$ closure of HAPU did not change the discharge destination in our population.

\section{Clinical relevance}

Knowledge about different time dynamics in occurrence of HAPU might lead to a reduction of HAPU in in-patient rehabilitation. Increased awareness and active prevention of HAPU are needed in the early phase of admission as we observed high occurrences especially in the first weeks of hospitalisation in readmitted patients. With the 
permanent risk in patients admitted for PU and first rehabilitation, repeated risk assessments or adapting awareness should be considered to evaluate changing risk factors during hospitalisation.

\section{Strength and weakness}

The advantage of this study is that it is based on careful clinical observations. However, the size of the patient group led to relatively small subgroups and results have to be interpreted with care. Secondly, as only basic patient characteristics without comorbidities were documented, important risk factors for occurrence and prolonged healing such as diabetes or peripheral arterial occlusive disease could not be analysed retrospectively. ${ }^{12,14}$ We recommend to analyse the presence of these contributing factors at the time of occurrence in future prospective studies. Thirdly, the results on time until closure only partially represent the reality because of missing observations of closure after discharge. High rates of skin worsening (51\%) after discharge are known, ${ }^{25}$ and hence we recommend an ongoing observation after discharge.

\section{CONCLUSION}

The dynamics in time until occurrence of HAPU varied according to admission reason and time since lesion. A constant awareness of the patient and caregivers is needed in all patient groups to prevent HAPU. The time until closure is difficult to predict because of wide time ranges and unclosed wounds at discharge. Further research including daily size measurement and risk factors might optimise prognosis, comparability and therefore judgement of quality of care.

\section{DATA ARCHIVING}

There were no data to deposit.

\section{CONFLICT OF INTEREST}

The authors declare no conflict of interest.

\section{ACKNOWLEDGEMENTS}

We thank all the professionals at the SPZ for contributing to the data collection and Adrian Wyss as the supervising nurse expert. We also thank Clara Sailer and Armin Gemperli for rereading and correcting the English language if necessary.

1 Verschueren JH, Post MW, de Groot S, van der Woude LH, van Asbeck FW, Rol M Occurrence and predictors of pressure ulcers during primary in-patient spinal cord injury rehabilitation. Spinal Cord 2011; 49: 106-112.

2 Scheel-Sailer A, Wyss A, Boldt C, Post MW, Lay V. Prevalence, location, grade of pressure ulcers and association with specific patient characteristics in adult spinal cord injury patients during the hospital stay: a prospective cohort study. Spinal Cord 2013; 51: 828-833.

3 Haisma JA, van der Woude LH, Stam HJ, Bergen MP, Sluis TA, Post MW et al. Complications following spinal cord injury: occurrence and risk factors in a longitudinal study during and after inpatient rehabilitation. J Rehabil Med 2007; 39: 393-398.

4 Gould LJ, Olney CM, Nichols JS, Block AR, Simon RM, Guihan M. Spinal cord injury survey to determine pressure ulcer vulnerability in the outpatient population. Med Hypotheses 2014; 83: 552-558.

5 Lupe L, Zambrana D, Cooper L. Prevention of hospital-acquired pressure ulcers in the operating room and beyond: a successful monitoring and intervention strategy program. Int Anesthesiol Clin 2013; 51: 128-146.

6 Schuurman J-P, Schoonhoven L, Defloor T, van Engelshoven I, van Ramshorst B, Buskens E. Economic evaluation of pressure ulcer care: a cost minimization analysis of preventive strategies. Nurs Econ 2009; 27: 390.

7 Wang H, Niewczyk P, DiVita M, Camicia M, Appelman J, Mix J et al. Impact of pressure ulcers on outcomes in inpatient rehabilitation facilities. Am J Phys Med Rehabil 2014; 93: 207-216.

8 Alderden J, Whitney JD, Taylor SM, Zaratkiewicz S. Risk profile characteristics associated with outcomes of hospital-acquired pressure ulcers: a retrospective review. Crit Care Nurse 2011; 31: 30-43.

9 Baumgarten M, Margolis DJ, Localio AR, Kagan SH, Lowe RA, Kinosian B et al. Pressure ulcers among elderly patients early in the hospital stay. J Gerontol A Biol Sci Med Sci 2006; 61: 749-754.

10 Fife C, Otto G, Capsuto EG, Brandt K, Lyssy K, Murphy K et al. Incidence of pressure ulcers in a neurologic intensive care unit. Crit Care Med 2001; 29: 283-290.

11 Bours G, Laat E, Halfens R, Lubbers M. Prevalence, risk factors and prevention of pressure ulcers in Dutch intensive care units. Intensive Care Med 2001; 27: 1599-1605.

12 Marin J, Nixon J, Gorecki C. A systematic review of risk factors for the development and recurrence of pressure ulcers in people with spinal cord injuries. Spinal Cord 2013; 51 : 522-527.

13 Lumbley JL, Ali SA, Tchokouani LS. Retrospective review of predisposing factors for intraoperative pressure ulcer development. J Clin Anesth 2014; 26: 368-374.

14 Hayes RM, Spear ME, Lee SI, Lupear BEK, Benoit RA, Valerio R et al. Relationship between time in the operating room and incident pressure ulcers: a matched casecontrol study. Am J Med Qual 2014; 30: 591-597.

15 Tew C, Hettrick H, Holden-Mount S, Grigsby R, Rhodovi J, Moore L et al. Recurring pressure ulcers: identifying the definitions. A National Pressure Ulcer Advisory Panel white paper. Wound Repair Regen 2014; 22: 301-304.

16 Van Asbeck F, Post M. Bedside prediction of the progress of pressure ulcer healing in patients with spinal cord injury using the 'Decu-stick'. Spinal Cord 2015; 53: 539-543.

17 Rappl LM. Physiological changes in tissues denervated by spinal cord injury tissues and possible effects on wound healing. Int Wound J 2008; 5: 435-444.

18 Eberlein T. Development of a new wound documentation system: making quality visible-achieving legal security. Pflege Zeitschrift 2006; 59: 359-361.

19 Probst W, Vasel-Biergans A. Wundmanagement. Wissenschaftliche Verlagsanstalt: Stuttgart. 2004.

20 Moffat C, Flanagan M, Falanga V. Positions document in der Praxis der European Wound Management Association EWMA, 2004.

21 NPUAP/EPUAP/PPPIA. Prevention and Treatment of Pressure Ulcers: Quick Reference Guide, 2014.

22 Jensen M, Truitt A, Schomer K, Yorkston K, Baylor C, Molton I. Frequency and age effects of secondary health conditions in individuals with spinal cord injury: a scoping review. Spinal Cord 2013; 51: 882-892.

23 Bergstrom N, Smout R, Horn S, Spector W, Hartz A, Limcangco MR. Stage 2 pressure ulcer healing in nursing homes. J Am Geriatr Soc 2008; 56: 1252-1258.

24 Van Rijswijk L, Polansky M. Predictors of time to healing deep pressure ulcers. Ostomy Wound Manage 1994; 40: 40-42 44, 46-48 passim.

25 Guihan M, Garber SL, Bombardier CH, Durazo-Arizu R, Goldstein B, Holmes SA Lessons learned while conducting research on prevention of pressure ulcers in veterans with spinal cord injury. Arch Phys Med Rehabil 2007; 88: 858-861.

Supplementary Information accompanies this paper on the Spinal Cord website (http://www.nature.com/sc) 